\title{
Individual and occupational determinants of low back pain according to various definitions of low back pain
}

Anna Ozguler, Annette Leclerc, Marie-France Landre, Françoise Pietri-Taleb, Isabelle Niedhammer

\begin{abstract}
Objectives-To test associations between non-specific low back pain and several risk factors when definitions of low back pain vary.

Design/setting/participants-A cross sectional study was set up in 1991, 725 workers from four occupational sectors answered a self administrated questionnaire including the Nordic questionnaire and questions about intensity of pain and individual and occupational factors.

Main results-Prevalence of low back pain varied from $8 \%$ to $45 \%$ according to the definition used. Psychosomatic problems, bending or carrying loads were often associated to low back pain, whereas other risk factors were related to some specific dimensions of the disorder.

Conclusions-Risk factors of low back pain vary with the definition. This could explain inconsistencies found in literature reviews. To be able to compare data, it seems important to be precise what definition is used and to use comparable questionnaires.

(F Epidemiol Community Health 2000;54:215-220)
\end{abstract}

Non-specific low back pain (LBP) is a common health problem, which has several definitions most often based on answers to questionnaires, use of medical services or sick leave. Many epidemiological studies have been carried out in order to specify the role of individual and occupational factors as possible causes. However, many results are inconsistent. Burdorf and Sorock ${ }^{1}$ listed potential risk factors with positive or negative association in a selection of 35 publications. In this review, no individual risk factor could be clearly pointed out: results on the role of age, gender and obesity showed inconsistent evidence. More consistency in the results is observed for work related risk factors, such as lifting, twisting, bending, exposure to whole body vibration or prolonged postures. ${ }^{2-4}$ For psychological and psychosocial risk factors, many studies conclude to a relation with LBP. $^{56}$

Leboeuf-Yde et al suggested two possible explanations for inconsistencies between studies: the association is true but weak, or non-specific LBP is a vague term concealing a multitude of conditions, some or all with different aetiologies.

In fact, there is no consensual definition of $\mathrm{LBP}^{28}$ and many dimensions can be taken into account such as duration of LBP, sick leave or visit to a health professional for LBP. ${ }^{9-13}$

The objective of this study was to test the hypothesis that the associations between prevalence of LBP and several risk factors differ according to the definition of LBP, and to examine which associations were observed irrespective of the definition. Here, the term "definition" is used as a substitute for dimension, each dimension being a possible definition of LBP in an epidemiological study.

This cross sectional study was part of a longitudinal survey in several occupational groups. $^{14} 15$

\section{Methods}

POPULATION

The sample comprised 725 active workers from four occupational sectors (office, hospital, warehouse, airport registration of luggage). The subjects came from a target population of 891 subjects, taken in charge by 10 medical services in charge of several companies in different regions of France, in 1991, whether they had LBP or not. Forty three subjects were excluded from the target population for the following reasons: sick leave longer than three months in the previous 12 months irrespective of the cause and duration of employment less than one year. Of the remaining 848,725 subjects $(85 \%)$ agreed to complete a self administrated questionnaire. Among the 123 who did not complete the questionnaire, 51 came from the same company and could not complete it for organisational reasons; $48(6 \%)$ refused and 24 were not able to fill in it for other reasons.

\section{LOW BACK PAIN DEFINITIONS}

The questionnaire concerned symptoms involving low back with additional questions about the intensity of pain. It included a French version of the Nordic questionnaire for the analysis of musculoskeletal symptoms to document symptoms during the preceding six months with a diagram of the lumbar area. ${ }^{16}$

The workers completed the questionnaire by themselves at the medical service of the company. Six different definitions have been used to define LBP (basically ache, pain or discomfort in a lumbar area whether or not it extended from there to one or both legs) in the previous six months: pain at least one day; pain at least 30 days; intensity of pain above 3 on a visual analogue scale from 0 to 7 ; visit to a health professional (doctor or physiotherapist); taking a treatment for LBP (drugs and other 
Table 1 Description of individual and occupational risk factors

\begin{tabular}{|c|c|c|c|c|}
\hline & \multicolumn{2}{|c|}{$\begin{array}{l}\text { Men } \\
(n=368)\end{array}$} & \multicolumn{2}{|c|}{$\begin{array}{l}\text { Women } \\
(n=357)\end{array}$} \\
\hline & $n$ & $\%$ & $n$ & $\%$ \\
\hline \multicolumn{5}{|l|}{ Age (y) } \\
\hline$<30$ & 89 & 24.2 & 103 & 28.9 \\
\hline 30-39 & 147 & 39.9 & 139 & 38.9 \\
\hline $40-49$ & 100 & 27.2 & 83 & 23.2 \\
\hline$>49$ & 32 & 8.7 & 32 & 9.0 \\
\hline \multicolumn{5}{|l|}{ Height (m) } \\
\hline$<1.63$ & 12 & 3.3 & 142 & 47.2 \\
\hline $1.63-1.68$ & 54 & 14.7 & 150 & 35.5 \\
\hline $1.69-1.74$ & 117 & 32.0 & 53 & 15.0 \\
\hline$>1.74$ & 183 & 50.0 & 9 & 2.3 \\
\hline \multicolumn{5}{|l|}{ BMI $\left(\mathrm{kg} / \mathrm{m}^{2}\right)$} \\
\hline$<20.58$ & 38 & 10.4 & 141 & 39.9 \\
\hline $20.58-22.59$ & 74 & 20.3 & 106 & 30.0 \\
\hline $22.60-24.92$ & 124 & 34.1 & 55 & 15.6 \\
\hline$>24.92$ & 128 & 35.2 & 51 & 14.5 \\
\hline \multicolumn{5}{|l|}{ Smoking status } \\
\hline Smoker & 159 & 43.5 & 124 & 34.8 \\
\hline Non-smoker & 151 & 41.4 & 204 & 57.3 \\
\hline Ex smoker & 55 & 15.1 & 28 & 7.9 \\
\hline \multicolumn{5}{|l|}{ PWB score } \\
\hline 0 & 129 & 36.6 & 91 & 27.2 \\
\hline 1 & 95 & 27.0 & 99 & 29.6 \\
\hline 2 & 65 & 18.5 & 68 & 20.4 \\
\hline$\geqslant 3$ problems & 63 & 17.9 & 76 & 22.8 \\
\hline \multicolumn{5}{|l|}{ Educational level } \\
\hline Low & 195 & 57.7 & 84 & 24.1 \\
\hline Medium & 61 & 18.0 & 101 & 28.9 \\
\hline High & 82 & 24.3 & 164 & 47.0 \\
\hline \multicolumn{5}{|l|}{ Occupational groups } \\
\hline Office workers & 129 & 35.0 & 158 & 44.3 \\
\hline Hospital workers & 16 & 4.4 & 137 & 38.4 \\
\hline Warehouse workers & 214 & 58.1 & - & - \\
\hline Airport registration workers & 9 & 2.5 & 62 & 17.3 \\
\hline \multicolumn{5}{|l|}{ Pulling or pushing heavy loads } \\
\hline Once a week or less & 216 & 58.7 & 246 & 68.9 \\
\hline More than once a week & 152 & 41.3 & 111 & 31.1 \\
\hline \multicolumn{5}{|l|}{ Carrying heavy loads } \\
\hline Once a week or less & 164 & 44.6 & 201 & 56.3 \\
\hline More than once a week & 204 & 55.4 & 156 & 43.7 \\
\hline \multicolumn{5}{|l|}{ Driving } \\
\hline Never or seldom & 214 & 58.2 & 316 & 88.5 \\
\hline Often or everyday & 154 & 41.8 & 41 & 11.5 \\
\hline \multicolumn{5}{|l|}{ Trunk rotations } \\
\hline Never or seldom & 177 & 48.1 & 121 & 33.9 \\
\hline Often or everyday & 191 & 51.9 & 236 & 66.1 \\
\hline \multicolumn{5}{|l|}{ Bending posture } \\
\hline Never or seldom & 147 & 39.9 & 142 & 39.8 \\
\hline Often or everyday & 221 & 60.1 & 215 & 60.2 \\
\hline
\end{tabular}

medical treatment, including non-prescribed drugs); sick leave for LBP.

For each definition, subjects classified as cases according to the definition were compared with the rest of the sample. The comparison of cases and non-cases for intense pain was based on 579 subjects instead of 725 , as 146 subjects did not answer the question on pain intensity. Missing data were equally distributed according to sex and occupational group.
INDIVIDUAL AND OCCUPATIONAL RISK FACTORS A list of risk factors was established according to results from the literature and the relations observed in the data set. ${ }^{2}{ }^{8}$ The data set included the following variables from the self administrated questionnaire (table1): sex; age (29 years or less; $30-39 ; 40-49 ; 50$ or more); body mass index (BMI) calculated by weight $(\mathrm{kg}) /$ height $^{2}\left(\mathrm{~m}^{2}\right)$, and divided into quartiles; score of psychosomatic well being (PWB) from 0 to 8 ; the questions about psychosomatic problems were derived from Langner's screening questionnaire. ${ }^{17}{ }^{18}$ This score based on the number of answers expressing presence of psychosomatic problems has been used in previous studies. ${ }^{14}{ }^{19}$ It is partly an indicator of psychological stress and partly of physiological malaise. It was divided into four categories of similar size; occupational groups: office workers, hospital workers, warehouse workers and airport registration workers; occupational factors: pulling or pushing heavy loads, carrying heavy loads (more than $10 \mathrm{~kg}$ ), driving more than two hours a day, trunk rotations, and bending forward or backward. These activities referred to the present job. For each of these variables, two categories were used as indicated in table 1 .

Some risk factors were not included in the models, as they were not related to LBP in this study: smoking, having children under 3 years old, height and educational level.

ANALYSIS

The analysis was based on six backward stepwise logistic regression models with the LBP definitions as dependent variables and the individual and occupational risk factors as independent variables. Sex was forced in the models because it was strongly related to occupation. At the first step, the model included all the independent variables. At each step, terms with $p$ level above 0.15 were removed and the $p$ level for re-entry was 0.10 . The final models included factors associated with LBP at a $\mathrm{p}$ level of 0.15 .

The analysis was performed using the BMDP software. ${ }^{20}$

\section{Results}

DESCRIPTION OF THE POPULATION

The sex ratio was about 1 with differences between occupational groups: all warehouse workers were men, whereas hospital and airport workers were mainly women.

Table 2 Six month prevalence of LBP according to different definitions

\begin{tabular}{|c|c|c|c|c|c|c|c|c|c|c|c|c|}
\hline & \multicolumn{6}{|c|}{ According to each definition } & \multicolumn{6}{|c|}{ According to two definitions * } \\
\hline & \multicolumn{2}{|c|}{$\begin{array}{l}M e n \\
(n=368)\end{array}$} & \multicolumn{2}{|c|}{$\begin{array}{l}\text { Women } \\
(n=357)\end{array}$} & \multicolumn{2}{|c|}{$\begin{array}{l}\text { Whole } \\
\text { sample }\end{array}$} & \multirow{2}{*}{$\begin{array}{l}\text { LBP at } \\
\text { least } 1 \text { day } \\
\%\end{array}$} & \multirow{2}{*}{$\begin{array}{l}\text { LBP at least } \\
30 \text { days } \\
\%\end{array}$} & \multirow{2}{*}{$\begin{array}{l}\text { Intensity } \\
\text { above } 3 \\
\%\end{array}$} & \multirow{2}{*}{$\begin{array}{l}\text { Taking } \\
\text { treatment } \\
\%\end{array}$} & \multirow{2}{*}{$\begin{array}{l}\text { Visit health } \\
\text { professional } \\
\%\end{array}$} & \multirow{2}{*}{$\begin{array}{l}\text { Sick leave } \\
\%\end{array}$} \\
\hline & $n$ & $\%$ & $\bar{n}$ & $\%$ & $n$ & $\%$ & & & & & & \\
\hline LBP at least 1 day & 150 & 40.8 & 162 & 45.4 & 312 & 43.03 & 43.03 & 17.10 & 33.16 & 20.41 & 20.83 & 8.14 \\
\hline LBP at least 30 days & 57 & 15.5 & 67 & 18.8 & 124 & 17.10 & & 17.10 & 16.93 & 11.17 & 11.59 & 4.14 \\
\hline Intensity above 3 & 103 & 34.8 & 100 & 35.3 & 203 & 35.06 & & & 35.06 & 20.55 & 22.28 & 9.33 \\
\hline Taking treatment & 75 & 20.4 & 82 & 23.0 & 160 & 21.66 & & & & 21.66 & 16.55 & 7.59 \\
\hline Visit health professional & 76 & 20.7 & 90 & 25.2 & 166 & 22.90 & & & & & 22.90 & 8.41 \\
\hline Sick leave & 35 & 9.5 & 28 & 7.8 & 63 & 8.69 & & & & & & 8.69 \\
\hline
\end{tabular}

*The prevalence figures in italic are the percentage of subjects that would be classified as having LBP according to both definitions line and column of the table. 
Table 3 Risk factors of LBP as defined by pain duration of at least one day $(n=680)$

\begin{tabular}{|c|c|c|c|}
\hline Predictor & $O R$ & $95 \% C I$ & Statistical significance \\
\hline Sex & & & $\mathrm{p}=0.958$ \\
\hline Men & 1 & & \\
\hline Women & 1.01 & $0.64,1.60$ & \\
\hline $\mathrm{BMI}\left(\mathrm{kg} / \mathrm{m}^{2}\right)$ & & & $\mathrm{p}=0.112$ \\
\hline$<20.58$ & 1.00 & & \\
\hline $20.58-22.59$ & 0.95 & $0.58,1.48$ & \\
\hline $22.60-24.92$ & 1.38 & $0.83,2.21$ & \\
\hline$>24.92$ & 1.58 & $0.94,2.55$ & \\
\hline PWB score & & & $\mathrm{p}=0.001$ \\
\hline 0 & 1.00 & & \\
\hline 1 & 1.37 & $0.90,2.08$ & \\
\hline 2 & 2.30 & $1.46,3.63$ & \\
\hline$\geqslant 3$ problems & 2.60 & $1.65,4.09$ & \\
\hline Occupational groups & & & $\mathrm{p}=0.065$ \\
\hline Office workers & 1.00 & & \\
\hline Hospital workers & 1.13 & $0.62,2.04$ & \\
\hline Warehouse workers & 0.54 & $0.30,0.96$ & \\
\hline Airport registration workers & 0.86 & $0.44,1.65$ & \\
\hline Carrying heavy loads & & & $\mathrm{p}=0.004$ \\
\hline Once a week or less & 1.00 & & \\
\hline More than once a week & 2.01 & $1.25,3.23$ & \\
\hline
\end{tabular}

Estimated odds ratio (OR) and their $95 \%$ confidence intervals $(95 \% \mathrm{CI}$ ) based on logistic regression. Sex forced in the model.

Mean age was 36 years, with similar figures for men and women. The BMI was lower for women. Concerning the PWB score, women had higher scores of psychosomatic problems than men (mean score 1.59 versus 1.34, $\mathrm{p}=0.03$ ). Heavy physical work was frequent in the studied population (table 1)

SIX MONTH PREVALENCE OF LBP ACCORDING TO DIFFERENT DEFINITIONS

The prevalence of LBP depended on the definition, with higher prevalence for very extensive definition (LBP at least one day). For men, the range of prevalence was from $40.8 \%$ (LBP at least one day) to $9.5 \%$ (sick leave for LBP in the previous six months). For women, numbers were similar, from $45.4 \%$ (LBP at least one day) to $7.8 \%$ (sick leave). The right part of table 2, indicating prevalence for definitions based on simultaneous occurrence of two dimensions of LBP, shows that none of the definition is a good predictor of others.

Table 4 Risk factors of LBP, as defined by pain duration of at least 30 days $(n=680)$

\begin{tabular}{|c|c|c|c|}
\hline Predictor & $O R$ & $95 \% C I$ & $\begin{array}{l}\text { Statistical } \\
\text { significance }\end{array}$ \\
\hline Sex & & & $\mathrm{p}=0.035$ \\
\hline Men & 1.00 & & \\
\hline Women & 1.69 & $1.04,2.76$ & \\
\hline Age (y) & & & $\mathrm{p}=0.018$ \\
\hline$<30$ & 1.00 & & \\
\hline $30-39$ & 1.60 & $0.86,2.97$ & \\
\hline $40-49$ & 2.35 & $1.22,4.53$ & \\
\hline$>49$ & 3.33 & $1.43,7.75$ & \\
\hline $\mathrm{BMI}\left(\mathrm{kg} / \mathrm{m}^{2}\right)$ & & & $\mathrm{p}=0.108$ \\
\hline$<20.58$ & 1.00 & & \\
\hline $20.58-22.59$ & 1.09 & $0.56,2.12$ & \\
\hline $22.60-24.92$ & 1.98 & $1.02,3.84$ & \\
\hline$>24.92$ & 1.79 & $0.91,3.52$ & \\
\hline PWB score & & & $\mathrm{p}=0.003$ \\
\hline 0 & 1.00 & & \\
\hline 1 & 1.31 & $0.72,2.40$ & \\
\hline 2 & 2.03 & $1.10,3.74$ & \\
\hline$\geqslant 3$ problems & 2.83 & $1.57,5.10$ & \\
\hline Driving & & & $\mathrm{p}=0.097$ \\
\hline Never or seldom & 1.00 & & \\
\hline Often or everyday & 1.53 & $0.93,2.53$ & \\
\hline Bending posture & & & $\mathrm{p}=0.007$ \\
\hline Never or seldom & 1.00 & & \\
\hline Often or everyday & 1.88 & $1.18,3.01$ & \\
\hline
\end{tabular}

Estimated odds ratio (OR) and their $95 \%$ confidence intervals ( $95 \% \mathrm{CI}$ ) based on logistic regression. Sex forced in the model.
Table 5 Risk factors of LBP as defined by pain intensity over $3(n=549)$

\begin{tabular}{llll}
\hline Predictor & OR & $95 \%$ CI & $\begin{array}{l}\text { Statistical } \\
\text { significance }\end{array}$ \\
\hline $\begin{array}{l}\text { Sex } \\
\text { Men }\end{array}$ & 1 & & $\mathrm{p}=0.517$ \\
$\quad$ Women & 0.86 & $0.56,1.34$ & \\
PWB score & & & $\mathrm{p}=0.002$ \\
$\quad 0$ & 1.00 & & \\
1 & 1.65 & $0.90,3.03$ & \\
2 & 2.86 & $1.54,5.31$ & \\
$\quad$ 3 problems & 2.77 & $1.47,5.20$ & \\
Bending posture & & & $\mathrm{p}=0.003$ \\
$\quad$ Never or seldom & 1.00 & & \\
$\quad$ Often or everyday & 2.14 & $1.30,3.50$ & \\
\end{tabular}

Estimated odds ratio (OR) and their $95 \%$ confidence intervals ( $95 \%$ CI) based on logistic regression. Sex forced in the model.

RISK FACTORS FOR LBP ACCORDING TO DEFINITION

Tables 3 to 8 give the results of the final models for the six definitions of LBP. The final models include factors associated with LBP at a $p$ level of 0.15 . Sex has been forced in the models.

Pain at least one day

Concerning LBP at least one day, which corresponded to a low threshold for definition of LBP, BMI, PWB score, occupational group and carrying loads remained in the final model. The prevalence of LBP tended to increase with increasing BMI. Having a high score of psychosomatic problems and carrying loads were risk factors of LPB. With this definition, belonging to the group of warehouse workers was protective (table 3 ).

Pain at least 30 days

With the threshold of 30 days for duration of pain, factors associated in the model were still PWB, BMI, but also sex, age, driving and bending. According to this definition, being a woman was a risk factor (table 4).

Intense pain

This definition corresponded to a LBP intensity over 3 on a visual analogue scale. The risk factors were the PWB score and bending (table $5)$.

Table 6 Risk factors of LBP as defined by visit to a health professional $(n=680)$

\begin{tabular}{|c|c|c|c|}
\hline Predictor & $O R$ & $95 \% C I$ & $\begin{array}{l}\text { Statistical } \\
\text { significance }\end{array}$ \\
\hline Sex & & & $\mathrm{p}=0.012$ \\
\hline Men & 1.00 & & \\
\hline Women & 1.71 & $1.13,2.60$ & \\
\hline $\mathrm{BMI}\left(\mathrm{kg} / \mathrm{m}^{2}\right)$ & & & $\mathrm{p}=0.005$ \\
\hline$<20.58$ & 1.00 & & \\
\hline $20.58-22.59$ & 0.90 & $0.50,1.60$ & \\
\hline $22.60-24.92$ & 2.10 & $1.19,3.69$ & \\
\hline$>24.92$ & 1.89 & $1.07,3.35$ & \\
\hline PWB score & & & $\mathrm{p}=0.001$ \\
\hline 0 & 1.00 & & \\
\hline 1 & 2.20 & $1.29,3.74$ & \\
\hline 2 & 3.01 & $1.72,5.29$ & \\
\hline$\geqslant 3$ problems & 3.43 & $1.97,5.96$ & \\
\hline Carrying heavy loads & & & $\mathrm{p}=0.001$ \\
\hline Once a week or less & 1.00 & & \\
\hline More than once a week & 2.06 & $1.40,3.04$ & \\
\hline
\end{tabular}

Estimated odds ratio (OR) and their 95\% confidence intervals ( $95 \% \mathrm{CI}$ ) based on logistic regression. Sex forced in the model. 
Visit to a health professional

Risk factors for this definition comprised sex (being a woman), BMI (over $22.60 \mathrm{~kg} / \mathrm{m}^{2}$ ), PWB score and carrying heavy loads (table 6).

Taking a treatment

In this model, the remaining factors were BMI (over $22.60 \mathrm{~kg} / \mathrm{m}^{2}$ ), PWB score, occupational group, carrying heavy loads and bending (table 7).

\section{Sick leave}

According to this definition, PWB score, occupational groups and bending posture were significantly related to LBP. Sex, BMI, pulling or pushing heavy loads and carrying heavy loads

Table 7 Risk factors of LBP as defined by taking a treatment $(n=680)$

\begin{tabular}{|c|c|c|c|}
\hline Predictor & $O R$ & $95 \% C I$ & Statistical significance \\
\hline Sex & & & $\mathrm{p}=0.161$ \\
\hline Men & 1.00 & & \\
\hline Women & 1.52 & $0.84,2.74$ & \\
\hline Age (y) & & & $\mathrm{p}=0.141$ \\
\hline$<30$ & 1.00 & & \\
\hline $30-39$ & 1.42 & $0.80,2.50$ & \\
\hline $40-49$ & 2.02 & $1.10,3.71$ & \\
\hline$>49$ & 1.58 & $0.69,3.63$ & \\
\hline $\mathrm{BMI}\left(\mathrm{kg} / \mathrm{m}^{2}\right)$ & & & $\mathrm{p}=0.014$ \\
\hline$<20.58$ & 1.00 & & \\
\hline $20.58-22.59$ & 1.17 & $0.62,2.18$ & \\
\hline $22.60-24.92$ & 2.03 & $1.09,3.79$ & \\
\hline$>24.92$ & 2.41 & $1.29,4.52$ & \\
\hline PWB score & & & $\mathrm{p}=0.001$ \\
\hline 0 & 1.00 & & \\
\hline 1 & 2.07 & $1.19,3.62$ & \\
\hline 2 & 2.86 & $1.59,5.14$ & \\
\hline$\geqslant 3$ problems & 3.70 & $2.08,6.58$ & \\
\hline Occupational groups & & & $\mathrm{p}=0.145$ \\
\hline Office workers & 1.00 & & \\
\hline Hospital workers & 0.96 & $0.44,2.07$ & \\
\hline Warehouse workers & 0.72 & $0.33,1.58$ & \\
\hline Airport registration workers & 0.34 & $0.11,1.02$ & \\
\hline Carrying heavy loads & & & $\mathrm{p}=0.012$ \\
\hline Once a week or less & 1.00 & & \\
\hline More than once a week & 2.17 & $1.17,4.00$ & \\
\hline Bending posture & & & $\mathrm{p}=0.115$ \\
\hline Never or seldom & 1.00 & & \\
\hline Often or everyday & 1.50 & $0.90,2.47$ & \\
\hline
\end{tabular}

Estimated odds ratio (OR) and their 95\% confidence intervals (95\% CI) based on logistic regression. Sex forced in the model.

Table 8 Risk factors of LBP as defined by sick leave $(n=680)$

\begin{tabular}{|c|c|c|c|}
\hline Predictor & $O R$ & $95 \% C I$ & Statistical significance \\
\hline Sex & & & $\mathrm{p}=0.076$ \\
\hline Men & 1.00 & & \\
\hline Women & 2.31 & $0.88,6.05$ & \\
\hline $\mathrm{BMI}\left(\mathrm{kg} / \mathrm{m}^{2}\right)$ & & & $\mathrm{p}=0.077$ \\
\hline$<20.58$ & 1.00 & & \\
\hline $20.58-22.59$ & 1.49 & $0.56,3.99$ & \\
\hline $22.60-24.92$ & 2.79 & $1.07,7.26$ & \\
\hline$>24.92$ & 2.79 & $1.07,7.25$ & \\
\hline PWB score & & & $\mathrm{p}=0.010$ \\
\hline 0 & 1.00 & & \\
\hline 1 & 3.19 & $1.34,7.59$ & \\
\hline 2 & 3.01 & $1.19,7.57$ & \\
\hline$\geqslant 3$ problems & 3.79 & $1.53,9.35$ & \\
\hline Occupational groups & & & $\mathrm{p}=0.039$ \\
\hline Office workers & 1.00 & & \\
\hline Hospital workers & 0.43 & $0.13,1.37$ & \\
\hline Warehouse workers & 1.66 & $0.51,5.40$ & \\
\hline Airport registration workers & 0.25 & $0.05,1.33$ & \\
\hline Pulling or pushing heavy loads & & & $\mathrm{p}=0.130$ \\
\hline Once a week or less & 1.00 & & \\
\hline More than once a week & 0.57 & $0.28,1.17$ & \\
\hline Carrying heavy loads & & & $\mathrm{p}=0.122$ \\
\hline Once a week or less & 1.00 & & \\
\hline More than once a week & 2.02 & $0.81,5.04$ & \\
\hline Bending posture & & & $\mathrm{p}=0.023$ \\
\hline Never or seldom & 1.00 & & \\
\hline Often or everyday & 2.33 & $1.10,4.92$ & \\
\hline
\end{tabular}

Estimated odds ratio (OR) and their $95 \%$ confidence intervals $(95 \% \mathrm{CI}$ ) based on logistic regression. Sex forced in the model.
KEY POINTS

- Risk factors of non-specific low back pain vary according to publications.

- There is no consensual definition of low back pain.

- In this study, risk factors of low back pain vary with its definition.

- Definition of low back pain should be explicit and comparable questionnaires should be used.

were also kept in the model $(\mathrm{p}<0.15)$. Pulling or pushing tended to be a protective factor of sick leave for LBP (table 8).

\section{Discussion}

The results suggest that risk factors of LBP vary according to the definition. Among well known classic individual and occupational factors, a few remained in most of the final regression models whereas other risk factors were associated only with some specific dimensions. Some of the negative findings might be attributable to a small number of cases with some definitions. However, this might explain only a part of the negative results, as the number and the strength of the associations with risk factors are not clearly related to the number of cases.

This was a cross sectional study, relations might be different in a longitudinal survey. Burdorf and Sorock ${ }^{1}$ in their review noted that cross sectional studies may underestimate some relations (change in job as a consequence of back pain) or overestimate them (subjects with LBP overstate their physical load). This study had several other limits: the data on occupational hazards and LBP were self reported, without validation from independent sources. They relied on retrospective recalling of pain, consultation, treatment or sick leave, over a six months period. Because of the relatively small size of the sample, separate analyses for men and women were not performed. All these dimensions may be considered as potential limitations or biases in the study of risk factors of LBP. For example, the healthy worker effect might explain the inverse association observed between pulling and pushing heavy loads and sick leave for LBP. The consequences of these limitations in the data are not obvious in this study, as the main objective was to compare results between different definitions of LBP.

Concerning individual factors, age and gender were not risk factors with several definitions of LBP, being a woman concerned the care dimension (visit to a health professional) and chronic LBP (pain duration of at least 30 days), being older than 40 was a risk factor for chronic LBP. The relation between age and chronic LBP, over 40 or 50 with a decrease of occurrence over 60 , is considered as an established fact in many reviews. ${ }^{12} 21$ The explanation is the presence of a degenerative process and accumulation of spinal damage. This relation was found in some recent studies $^{3910}$ but not in all of them. ${ }^{27}$ 
The role of gender for common LBP is complex. ${ }^{21}$ Being a woman is considered as a risk factor in some studies ${ }^{11} 23$; while being a man is a risk factor in other studies. ${ }^{913}$ Concerning the relation between gender and visit to a health professional, our results are in accordance with other studies; in general women visit a doctor more frequently ${ }^{10}$ and consult more for LBP: $6 \%$ of female compared with $4 \%$ of male ${ }^{11}$ consult a GP for LBP.

The BMI was a risk factor for both definitions based on medical care (visit to a health professional and treatment). Subjects with a BMI of $22.60 \mathrm{~kg} / \mathrm{m}^{2}$ or more were more likely to visit a health professional and to take a treatment. Previous studies showed inconsistent evidence on the role of weight and obesity. ${ }^{2821}$

Psychosomatic factors (PWB score) were a risk factor of LBP for all the definitions taken into account in this study. Bongers et $a l,^{5}$ in a review, stated that personality traits, emotional problems and stress symptoms were associated with back trouble in a large number of studies based on various definitions of LBP.

In this study, few associations were found between occupation and LBP taking into account other occupational hazards: warehouse workers reported less LBP lasting at least one day. Warehouse workers and hospital workers occupations are considered high risk occupations. ${ }^{22} 251$ The results showing that fewer warehouse workers declared LBP lasting at least one day might be because of the inclusion of "carrying loads" (table 3). Another possible explanation would be that minor spells of LBP are underreported among warehouse workers. Occupation reflects different dimensions, including both physical demands and psychosocial aspects of work. The constraints of the labour market may also induce underreporting of LBP among some specific occupational fields.

Concerning work related risk factors, carrying heavy loads and frequent bending were the most emergent factors in this study. These two risk factors are not independent, but in this study one of these risk factors could not replace the other one in the models. These findings agree with the review by Burdorf and Sorock $^{1}$ who described positive associations between lifting loads and bending in most of the reviewed articles.

Carrying loads over $10 \mathrm{~kg}$ was associated with pain duration over one day, visit to a health professional and taking a treatment for LBP. Pietri et $a l^{19}$ found an association between carrying loads and pain duration over one day. An association between carrying loads ( $>25 \mathrm{lb}$ (approximately $11.34 \mathrm{~kg}$ )) and consulting a general practitioner for LBP was found by Macfarlane ${ }^{11}$ for women only.

Bending posture was associated with pain intensity over 3 and sick leave. Driving more than two hours a day was a risk factor for "chronic" LBP (at least 30 days). Associations between driving and LBP have been observed but not specifically for chronic LBP. ${ }^{19}$

The first results in this study are that conclusions concerning risk factors of LBP depend on the definition. Some risk factors such as psychosomatic problems, bending posture or carrying loads seem to be less sensitive to a change in the definition. For other risk factors, the data support the hypothesis of specific or stronger associations with one dimension of LBP: age and chronic LBP, sex and use of medical services for LBP, driving and chronic LBP. These results suggest more attention should be paid to the different dimensions of LBP in future studies, as well as to the use of comparable questionnaires, and more explicit definition of LBP used.

The nine occupational medicine services were the Centre Hospitalier Esquirol, Limoges (J Laplaud); Merlin-Gérin, Grenoble C Moesch, C Chapperon); Peugeot, Vesoul (S Perrin, P Vougnon); CMTIEOP, Paris (P Boulard, I Perier); EDF-GDF, Toulouse (C Roitg-Ladousse); Aéroports de Paris, RoissyCharles de Gaulle (V Gossot, R Alleaume); SMT, Niort (F Mesnard); AMETIF, Cergy-Pontoise (J Sohier, E De Feuardent); CMI, Paris (F Griscelli), Service Interentreprise, Bordeaux (M Cazaux).

Funding: the study was supported by the French Ministry of Labour and Social Affairs and the Ministry of Research, in cooperation with the Club Européen de la Santé.

Cooperation with the Club
Conflicts of interest: none.

1 Burdorf A, Sorock G. Positive and negative evidence of risk factors for back disorders. Scand 7 Work Environ Health 1997;23:243-56.

2 Riihimäki H. Low-back pain, its origin and risk indicators. Scand 7 Work Environ Health 1991;17:81-90.

3 Liira JP, Shannon HS, Chambers LW, et al. Long-term back problems and physical work exposures in the 1990 Ontario problems and physical work exposures in the 1990

4 Scientific Committee for musculoskeletal disorders of the International Commission on Occupational Health. Musculoskeletal disorders : work-related risk factors and prevention. Int f Occup Environ Health 1996;2:239-46.

5 Bongers P, de Winter CR, Kompier MAJ, et al. Psychosocial factors at work and musculoskeletal disease. Scand $\mathcal{f}$ Work Environ Health 1993;19:297-312.

6 Leino PI, Hänninen V. Psychosocial factors at work in relation to back and limb disorders. Scand $\mathcal{f}$ Work Environ Health 1995, 21:134-42.

7 Leboeuf-Yde C, Lauritsen JM, Lauritzen T. Why has the search for causes of low back pain largely been non conclusive? Spine 1997;22,877-81.

8 Coste J., Paolaggi JB. Revue critique de l'épidémiologie des lombalgies. Rev Epidemiol Sante Publ 1989;37:371-83.

9 Hildebrandt VH. Back pain in the working population : prevalence rates in Dutch trades and professions. Ergonomics 1995;38:1283-98.

10 Houtman ILD, Bongers P, Smulders PGW, et al. Psychosocial stressors at work and musculoskeletal problems. Scand cial stressors at work and musculoskeletal

11 MacFarlane GJ, Thomas E, Papageorgiou AC, et al. Employment and physical work activities as predictors of future low back pain. Spine 1997;22:1143-9.

12 Papageorgiou AC, MacFarlane GJ, Thomas E, et al. Psychosocial factors in the workplace - Do they predict new episodes of low back pain? :Evidence from the South Manchester Back Pain Study. Spine 1997;22:1137-42.

13 Walsh K, Varnes N, Osmond C, et al. Occupational causes of low-back pain. Scand 7 Work Environ Health 1989;15:54-9.

14 Leclerc A, Landre MF, Pietri F, et al. Evaluation of interventions for prevention of back, and shoulder disorders in three occupational groups. Inter f Occup Environ Health 1997;3:5-12.

15 Club européen de la santé, INSERM U88. Evaluation d'actions de prévention des rachialgies. Paris: Compte-rendu de fin de contrat, Ministère de la Recherche, 1994.

16 Kuorinka I, Jonsson B, Kilbom A, et al. Standardised Nordic questionnaire for the analysis of musculoskeletal sympquestionnaire for the analysis of m
toms. Appl Ergonom 1987;18:233-7.

17 Langner TS. A twenty-two item screening score of psychiatric symptoms indicating impairment. F Health Human Behaviour 1962;3:269-76.

18 Langner TS. The twenty-two item screening score of psychiatric symptoms. In: Mac Dowell I, Newell C. Measuring health: a guide to rating scales and questionnaires. 2nd ed. New York, Oxford University Press, 1996.

19 Pietri F, Leclerc A, Boitel L, et al. Low back pain in commercial travellers. Scand $\mathcal{f}$ Work Environ Health 1992;18:52-8.

20 BMDP Statistical Software Inc. BMDP Statistical Software Manual, Vol 2. Los Angeles, CA: BMDP Statistical Software Inc, 1990.

21 Dempsey PG, Burdorf A, Webster BS. The influence of personal variables on work-related low-back disorders and implications for future research. $\mathcal{F}$ Occup Environ Med 1997;39:748-59.

22 Niedhammer I, Lert F, Marne MJ. Back pain and associated factors in French nurses. Int Arch Occup Environ Health 1994;66:349-57. 
23 Hillman M, Rajaratnam G, Tennant A, et al. Prevalence of low back pain in the community : implications for service provision in Bradford, UK. I Epidemiol Community Health 1996;50:347-52.

$24 \mathrm{Xu}$ Y, Bach E, Orhede E. Work environment and low back pain : the influence of occupational activities. Occup Environ Med 1997;54:741-5.

25 Ahlberg-Hultén GK, Theorell T, Sigala F. Social support, job strain and musculoskeletal pain among female health care personnel. Scand $\mathcal{f}$ Work Environ Health 1995;21:435-9.

26 Burdorf A, Naaktgeboren B, de Groot HCWM. Occupational risk factors for low back pain among sedentary workers. F Occup Med 1993;35:1213-20.

27 Guo H, Tanaka S, Cameron LL, et al. Back pain among workers in the United States: national estimates and workers at high risk. Am f Ind Med 1995;28:591602 .

28 Harber P, Pena L, Hsu P, et al. Personal history, training, and worksites as predictors of back pain of nurses. Am f Ind Med 1994;25:519-26.

29 Hignett S. Work-related back pain in nurses. F Adv Nurs 1996;23:1238-46.

30 Leighton DJ, Reilly T. Epidemiological aspects of back pain : the incidence and prevalence of back pain in nurses compared to the general population. Occup Med 1995;45: 263-7.

31 Smedley E, Egger, P, Cooper C, et al. Manual handling activities and risk of low back pain in nurses. Occup Environ Med 1995;52:160-3. 